\title{
College English Teaching between Chinese and English Idioms
}

\author{
Shuo Zhao', Xin Zhang² \\ ${ }^{1}$ School of International Studies, Communication University of China, Beijing, China \\ ${ }^{2}$ Guangcai Primary School of Shan County, Heze, China \\ Email: 1754224618@qq.com, zhang599242294@foxmail.com
}

How to cite this paper: Zhao, S., \& Zhang, X. (2021). College English Teaching between Chinese and English Idioms. Open Journal of Social Sciences, 9, 470-475. https://doi.org/10.4236/jss.2021.912030

Received: November 24, 2021 Accepted: December 28, 2021 Published: December 31, 2021

\begin{abstract}
An idiom is a phrase which is an established and fixed part of a particular language. Idioms are the essence of language and they bear the cultural characteristics and cultural information of a nation. The culture differences reflected in idioms are mainly shown in four aspects. They are differences in context, custom, religion and history. Idioms' characteristics have a close relationship with source. The two languages between Chinese and English have some similar cultural characteristics. These differences and similarities make translation of idioms quite difficult. Therefore, cultural translation methods are very important. In order to have a better transmit in idioms culture, we should avoid making mistakes in idiom translation. English-Chinese translation is one of the important means of learning English, especially the translation of English idioms. Translators often need careful scrutiny, should not take the words literally. Making the translation of idioms is in line with the idioms using habits, but also with their implied meaning. This paper tries to analyze some idioms from the background knowledge. Therefore, discussion on correct understanding idioms is an important prerequisite for translation.
\end{abstract}

\section{Keywords}

Idiom Translation, Cultural Similarities, Cultural Differences, College English Teaching

\section{Definition of Idioms}

Idioms are the crystallization of human wisdom. It is the essence of language. Different people from different culture may have different understanding of the same sentence, because they know little about the mother culture. Due to lack of knowledge of cultural difference, we may encounter all kinds of problems. 
Idioms play an important role in cultural exchange. For another, as a mirror of culture, idioms is strongly reflected and shaped by culture (Baker, 2008). As an essential part of language and culture of a society, idioms are characterized by their concise expressions, rich and vivid, involving geography, history, religious belief and so on. They are usually specialized in meaning and closely tied to cultural features and cultural attitudes.

It is believed that idioms are the most culturally loaned elements in language vocabulary. They are often hard to understand and harder to translate correctly. English idioms and Chinese idioms that are closely related to their own culture and convey different cultural feature and messages of their nation. In order to translate English idioms into Chinese correctly, we should know the meaning of idioms and be aware of between the cultural features and emphasize the similarities and differences between English and Chinese idioms. We should study the methods of idiom translation and problems concerned in idioms translation.

\section{Similarities between English and Chinese Idioms}

Language is the carrier of culture. It reflects the culture and culture affects the language. We always say different culture has same origin. Chinese and English language has a long history, which contains a large number of vivid idioms. Because of the difference among geography, history, religion, customs and other aspects of life, both English and Chinese idioms carry different national cultural characteristics and cultural information.

\subsection{Same Form or Same Meaning}

Although English idioms and Chinese idioms have differences, these two kinds of culture of the people after all live together in the same earth. Environment and living environment is largely the same. They have a common cognition, regardless of the way of life, thinking habits and values, or the same point. Some Chinese are similar in English. In English, some things are also Chinese. For example, three meals a day, clothes etc. Since culture has many similarities, the two languages have a lot in common, which resulted in two languages translation. Idioms are crystallization of life experience, so the form in the English and Chinese is similar.

Strike while the iron is hot. (趁热打铁)

Great minds think alike. (英雄所见略同)

For this kind of idiom translation, we should find the corresponding translation of idioms and take the literal translation (Cullen, 2006). Because the two groups of idioms image are similar and the same meaning take this translation method, it not only can retain the original style, but also is convenient for the target language readers to accept.

\subsection{Different Form or Same Meaning}

Although English and Chinese live in the same environment largely, Specific 
living environment is a difference, and religious beliefs, social background and historical culture are different, therefore in the expression are different. So has the different but the same meaning of idioms. For example, Britain is an island country, marine industry is very developed, so many idioms are related with navigation.

Fish begins to stink at the head. (上梁不正下梁歪)

Never offer to teach fish to swim. (不要班门弄斧)

These two groups of idioms although have different forms, English is about the knowledge of fish while Chinese are about architecture and allusions, but their implied meaning is same. For this kind of idioms, the key is to find the target language corresponding idioms. Translation methods of idioms replace primitives. Of course, this need to have strong language skills, usage of idioms should be quite familiar with two languages. Otherwise it would be self-defeating.

\subsection{Similar Form or Different Meaning}

This idiom belongs to a class of more difficult, need to be especially careful treatment. Because of the differences of the two languages exist differences in culture, some idioms seem on the surface is the same, but the significance is far from. For example, seemingly not much difference between strange bed fellows and Chinese "strange bed fellows", but in fact the meaning is completely different, it is equivalent to "meet by chance". Also child's splay, don't take it as a "regard as a game", it says "do something very easy". There is all the more familiar pull one's leg and one's hair stands on end, which means "play a joke on somebody" and "fear", rather than "back" and "be up his hat".

For this kind of idioms, we cannot take the words too literally. We will check dictionary in order to understand the real meaning of idioms.

\section{Cultural Differences between English and Chinese Idioms}

\subsection{Differences of Living Context}

The forming of idioms closely is related to life and labor. UK is an island country whose people live along seacoast and dependent on the sea. So, English have lots of idioms about water. For example:

As close as an oyster. (守口如瓶)

Cast an anchor to windward. (未雨绸缪)

At sea. (茫然)

Tower one's sail. (甘拜下风)

To keep one's head above water. (奋力图存)

\subsection{Custom Differences}

Custom is a nation gradually formed in the long years. It reflected cultural awareness and performance, governed by the national psychological state. National customs is rich and colorful. It constitutes a rich heritage of idioms. They are deep soil for breeding and tenacious vitality. Many idioms come from folk. 
The Chinese idiom "piece of cake" and English idioms a piece of cake. "A piece of cake", said one thing is very easy. But in idioms, the expression of the two people on the same idea is in the form of a completely different way, which is related with their eating habits. The British dog, as a dog for a partner, therefore, we often see phenomenon with the dog's metaphor of life behavior of ordinary people. For example, love me, love my dog. Although China has dogs, most people hate this animal in the psychology. It is often described as bad deeds and metaphor.

Britain and China both have a long history. Culture is broad, profound and rich in folk legends and historical stories. A large part of the idioms come from it. For example, Cross the Rubicon (孤注一掷) has its source in the history of Roman story; castle in the air (空中楼阁) from myth; hang by a thread (千钧一 发) is derived from the Greek story (Homby, 1997).

\subsection{Religion Differences}

Religion is an important source of Idioms. Religion is a cultural phenomenon related to religion. Idioms in English and Chinese idioms reflect the influence of religion on language. Some English idioms mainly related to Christianity. For example, in the right church, but in the wrong pew. (进对了教堂, 但坐错了椅 子, 比喻总的来说是对的, 但细节上不对) God helps those who help themselves. (自助者, 天助也) God's mill goes slowly, but it grind well. (天网恢恢, 疏而不 漏) (Wikipedia, 2014) However, China is a multi-religious country, especially the influence of Buddhism, so Chinese idioms mainly came from Buddhism, temple, monk and so on, such as "back", "leisure time not to burn incense, cramming", "the monk may run away, but the temple can't" etc.

As a cultural phenomenon, religion, which is the manifestation of different cultures, is the vital part of human thought. It penetrates into every possible aspects of human life, while consequently causes great cultural differences between people with different religion belief. China is a multi-religion country, yet comparatively speak Buddhism has a greater influence in Chinese culture (Yu, 2010). For example (Wang, 2011),

To make a personal example as an effective means of convincing others. (现身 说法)

Switch to a new trade without solid foundation. (半路出家)

To save a human life is better than building a seven-storied pagoda. (救人一 命胜造七级浮屠)

Remained spotless. (一尘不染)

To present Buddha with borrowed flowers-to borrow something to make a gift of it. (借花献佛)

Take a passive attitude towards one's work. (作一天和尚, 撞一天钟)

\section{English and Chinese Idiom Teaching}

English idioms are loaded with a large amount of cultural information. They are 
the essence and indispensable part of language vocabulary (Wang, 2011). In order to help students learn and apply English better, we can start from the following aspects in the process of English and Chinese idiom teaching.

First of all, for teachers, to arouse students' interest, then the teaching method is half the success. We should know that interest is the best teacher to arouse students' interest in different cultural differences and encourage them to read extensively after class. For example, original English books or English movies, TV dramas, TV programs and so on, they can intuitively understand the cultural environment, behavior and customs of Western society.

Secondly, in the process of English idiom teaching, the most basic teaching method is to teach translation methods and skills, such as literal translation, free translation, etc.

Then, situational teaching can be carried out in the classroom. Teachers can design a scene for the students, such as birthday, party or friends meet each other when they meet, and so on, let the students imitate the westerners for dialogue.

Finally in the ordinary teaching, teachers can also use multimedia equipment to directly show the behavior and habits of westerners for students, and insert knowledge related to cultural differences while telling the knowledge points of the course. The model of English and Chinese idioms teaching methods is shown in Figure 1.

\section{Conclusion}

It is found that the idioms are unique and fixed part. It is not only the essence of language, but also has a profound history and cultural origins. They are concise and vivid. And they are frequently used in daily life. But due to the different cultural background, which reflects the great cultural differences in English and Chinese idioms, it also brought lot of difficulties to the translator. The translation of idioms has both the spirit of science and art style. The two characters make the reproduction of the original beauty. In addition, the idiom translation can also achieve the purpose of promoting cultural exchanges between Chinese and English.

Idioms are important factors in the language. It is the concentrated expression of special elements, national form in language and various kinds of rhetorical

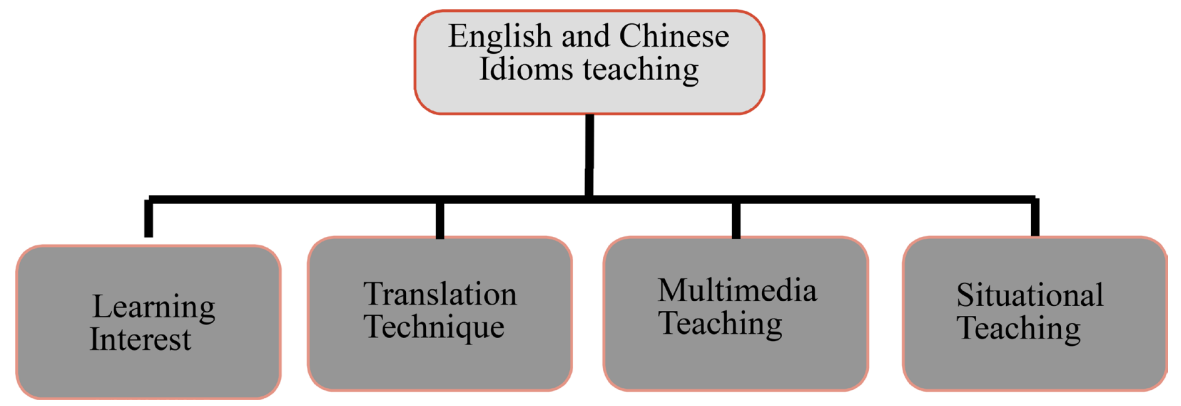

Figure 1. English and Chinese idiom teaching model. 
devices, so idiom processing is very important in translation. Although the translation of idioms is difficult sometimes, its translatability is still definitely. The translator should prevent translating word to word and the abuse of synonymic idioms. The two deviations must know the value of literal translation. The translation mainly relies on our own serious creative work according to the principle of unity and content in different situations. We can deal with it in a flexible way. With the Chinese idiom in different context, we must use different methods of translation to deal with it. In a word, the translation of idioms is one of the important aspects in the different cultural exchange.

\section{Acknowledgements}

The research is sponsored by team project of Research Promotion Program (No.SIS21T01) in School of International Studies, Communication University of China.

\section{Conflicts of Interest}

The authors declare no conflicts of interest regarding the publication of this paper.

\section{References}

Baker, M. (2008). Routledge Encyclopedia of Translation Studies. London \& New York: Routledge.

Cullen, K. (2006). Chambers Guide to Idioms. Beijing: Foreign Language Teaching and Research Press.

Homby, A. S. (1997). Oxford Advanced Learner's English-Chinese Dictionary. Beijing: The Commercial Press.

Yu, L. S. (2010). On Structure and Culture in the Translation of Chinese Idioms. Harbin: Heilongjiang University Press.

Wang, S. G. (2011). New English Idioms Dictionary. Beijing: China Renmin University Press.

Wikipedia (2014). Microlecture. http://en.wikipedia.org/wiki/Microlecture 